\title{
Clinical, pharmacokinetic and technological aspects of the hydroxychloroquine sulfate
}

\author{
Leslie Raphael de Moura Ferraz ${ }^{1}$; Fabiana Lícia Araújo dos Santos ${ }^{2}$; Pablo de \\ Ataíde Ferreira $^{3}$; Ricardo Tadeu Lourenço Maia Junior ${ }^{4}$; Talita Atanazio Rosa ${ }^{5}$, \\ Larissa Araújo Rolim ${ }^{6}$; Pedro José Rolim-Neto ${ }^{7}$. \\ ${ }^{I}$ Ph.D Student, Department of Pharmaceutical Sciences, Federal University of Pernambuco, Brazil \\ ${ }^{2}$ Ph.D Student, Department of Pharmaceutical Sciences, Federal University of Pernambuco, Brazil \\ ${ }^{3}$ Ph.D Student, Department of Pharmaceutical Sciences, Federal University of Pernambuco, Brazil \\ ${ }^{4}$ Graduate Student, Department of Pharmaceutical Sciences, Federal University of Pernambuco, Brazil \\ ${ }^{5}$ MSc. Student, Department of Pharmaceutical Sciences, Federal University of Pernambuco, Brazil \\ ${ }^{7}$ Professor, Pharmaceutical Sciences Collegiate, Federal University of Vale do São Francisco, Brazil \\ ${ }^{8}$ Professor, Department of Pharmaceutical Sciences, Federal University of Pernambuco, Brazil
}

\begin{abstract}
Developed originally as an antimalarial agent, hydroxychloroquine sulfate (HCQS) is often used as a slow-acting drug in treating disorders of connective tissue. Over the past two decades, several data have been accumulated on the systemic effects of HCQS, expanding the potential uses of this drug in different therapeutic classes. The purpose of this article was to conduct a narrative review with qualitative approach on clinical, pharmacokinetic and technological aspects of HCQS, aiming to gather relevant pieces of information for the development of new therapeutic approaches to this drug. A search of the literature of scientific experimental and theoretical studies in the period 1980-2013 was performed. According to the data collected, among the activities HCQS, there are the indications for the treatment of autoimmune diseases such as lupus erythematosus and rheumatoid arthritis. Reports also indicate that HCQS improves insulin sensitivity, ability to reduce thromboembolic events, reduction of lipid levels and treatment for infection by human immunodeficiency virus. The evidence found out ocular and cutaneous adverse effects and the formation of three chiral active metabolites, what encourages studies to evaluate the kinetic behavior of HCQS and the intrinsic physicochemical characteristics of the drug, which is yet poorly described in the literature.
\end{abstract}

KEYWORDS : Autoimmune Diseases, Chiral Drugs, HIV, Hydroxychloroquine Sulfate.

\section{INTRODUCTION}

Initially developed as an antimalarial agent, hydroxychloroquine sulfate (HCQS) - chemically 2-(\{4[(7-chloroquinolin-4-yl)amino]pentyl\}(ethyl)amino)ethan-1-ol - is often used as slow-acting antirheumatic drug in the treatment of disorders of connective tissue [1-3]. As antimalarial, hydroxychloroquine (HCQ) is significantly effective against the erythrocytic form of the etiological agents of malaria: Plasmodium vivax and Plasmodium malariae, and most of Plasmodium falciparum strains. However, recently some resistance has been observed to chloroquine-resistant Plasmodium falciparum, as well as cases of resistance against Plasmodium vivax strains. And, despite being used a long time ago in this type of therapy, it is not known its exact mechanism of action [4-5].

The HCQ has been used also as a secondary drug in the treatment of a variety of chronic diseases. So, they are administered in conjunction with other agents, resulting in clinical efficacy of diseases such as rheumatoid arthritis (RA), systemic lupus erythematosus (SLE), discoid lupus (LD), sarcoidosis, Sjögren's syndrome (SS) and photosensitivity diseases [5].The treatment of autoimmune diseases with anti-malarial have been common for over half a century. Many long-term studies show better results in terms of organ damage and overall survival of patients receiving these drugs. Over the past two decades, more data have been accumulated on the systemic effects of HCQS, expanding the potential uses of this medication in different therapeutic classes [1].The purpose of this article was to conduct a narrative review with qualitative feature on clinical, pharmacokinetic and technological aspects of HCQS, aiming to gather relevant information for development of new therapeutic approaches to this drug. 
It was performed a literature search of scientific experimental and theoretical studies in the period of 1980-2013. However, some previous publications of essential scientific relevance about the study topic were considered. All the sources surveyed integrate scientific articles that address the topic of HCQS, besides information from official sites and master or $\mathrm{PhD}$ thesis.

\section{CLINICAL ASPECTS}

The HCQS brings benefits to long term in the treatment of SLE and RA and has become a standard component of therapy for patients with these diseases. Table 1 provides a systematic overview of the effectiveness of treatment with HCQS on clinical manifestations of major diseases where the use of the drug is recommended.

Table 1. Systematic review of evidence of efficacy of HCQS in the treatment of RA and SLE [1].

\begin{tabular}{|c|c|c|c|}
\hline Illness & Evaluation of efficacy & Type of evidence & Reference \\
\hline \multirow[t]{3}{*}{ RA } & $\begin{array}{l}\text { Counting of joint swelling } \\
\text { and pain; }\end{array}$ & Systematic literature; & [6] \\
\hline & Articular index; & Controlled trial, double-blind; & [7] \\
\hline & Joint pain and sensitivity; & $\begin{array}{l}\text { Clinical randomized, controlled, } \\
\text { double-blind; }\end{array}$ & [8] \\
\hline \multirow[t]{8}{*}{ SLE } & Seizure frequency; & $\begin{array}{l}\text { Randomized, controlled, double- } \\
\text { blind, involving withdrawal of } \\
\text { therapy; }\end{array}$ & [9] \\
\hline & Organ failure; & $\begin{array}{l}\text { Longitudinal cohort study; case- } \\
\text { control study; }\end{array}$ & [10-11] \\
\hline & Survival; & $\begin{array}{l}\text { Analysis of prospective cohort; } \\
\text { Analysis of longitudinal cohort; }\end{array}$ & {$[12-13]$} \\
\hline & Late onset of the disease; & Nested case-control study; & {$[14]$} \\
\hline & Cutaneous manifestations; & Analysis of prospective cohort; & {$[15]$} \\
\hline & $\begin{array}{l}\text { Prevalence of new renal } \\
\text { disease; }\end{array}$ & Analysis of prospective cohort; & {$[13]$} \\
\hline & Glomerulonephritis; & Analysis of longitudinal cohort; & {$[16]$} \\
\hline & $\begin{array}{l}\text { Complete renal remission for } \\
\text { membranous nephropathy. }\end{array}$ & Retrospective cohort analysis; & {$[17]$} \\
\hline
\end{tabular}

Reports demonstrated the efficacy of HCQ in different conditions from those which have rheumatic diseases. Some of these reports are described below [1].The first information relates to diabetes mellitus. Hypoglycemic conditions in patients treated with HCQ and CQ has being observed. Three small clinical studies, randomized and controlled, using patients without other rheumatic complications and receiving a relatively high dose of HCQS $(600 \mathrm{mg})$ reinforced this situation [18].A brief prospective study with obese, non-diabetic and non-carriers of autoimmune diseases demonstrated an improvement of insulin sensitivity after six weeks of treatment with HCQ. These results suggest that there is not only a reduction in the incidence of type two 
diabetes in patients who are being treated with HCQS for other conditions, as well as in the rate of blood glucose and insulin resistance.

Probably, this effect of HCQ on the glucose is related to changes in the intra-endosomal $\mathrm{pH}$, which results in reduced degradation of insulin in human adipose tissue [1]; [19].Another interesting finding is the ability of HCQ to reduce thromboembolic events. Johnson \& Charnley (1979) [20] reported the usefulness of prophylactic HCQS to avoid significant thrombotic events in post-operative conditions of total hip arthroplasty. An analysis of prospective cohort demonstrated the protective effect of antimalarial drugs in development of thrombosis as well as significant improvement of survival. A more recent study - cohort-based analysis, using 1930 patients with SLE - examined factors that were associated with one or more thrombotic events, which showed that the use of HCQS was significantly associated with a risk reduced thrombosis, especially in young patients [12]; [21-24].

Several mechanisms have been proposed for the antithrombotic effects of HCQS. The most probable appears to be the reduction of platelet aggregation or the inhibition of the release of alpha granule, structures that have factors which participate in the coagulation cascade. However, these findings are limited to in vitro studies and the concentration necessary to be able to observe this effect $(25 \mathrm{mg} / \mathrm{ml})$ is 200 times higher than levels reported in the blood of treated patients [15]; [24-25].A reduction in cardiovascular risk, due to general beneficial effect on the lipid profile when treated with HCQS, has been recognized for decades. Petri and collaborators (1994) [26], in longitudinal cohort study showed a significant association between treatment with HCQS, with a dose of $200 \mathrm{mg}$ to $400 \mathrm{mg}$ per day, and lower cholesterol levels. Similar results were obtained by Rahman and collaborators (1999) [27], emphasizing the recovery of cholesterol levels when in discontinuation of the therapy. Thus, recent studies have proved reducing lipid levels, total cholesterol and even low density lipoproteins in patients with RA or SLE, who are treated with the drug in question, for relatively short periods [28-33].

The mechanisms responsible for changes in the lipid profile with HCQS are not well elucidated. Studies have postulated that this is due to significantly higher rate of clearance of lipid fractions or even to upregulation of low-density lipoprotein receptor [34].Perhaps the most unexpected factor is the large amount of published literature documenting the use of antimalarials, especially HCQS, in the treatment of infection with the human immunodeficiency virus (HIV). Just over a decade, two controlled clinical trials have demonstrated the efficacy of HCQS in this illness.The first of these, a placebo-controlled study, which 40 patients with $\mathrm{CD}^{+} \mathrm{T}$ lymphocytes levels greater than 200 cells $/ \mathrm{mm}^{3}$ were randomized to receive $800 \mathrm{mg} / \mathrm{day}$ of HCQS or placebo for 8 weeks. The treated group showed a significant decline in levels of viral ribonucleic acid (RNA), while this value was higher in the group treated with placebo. The percentage of $\mathrm{CD}^{+} \mathrm{T}$ cells remained stable [35].The second study featured 72 seropositive HIV patients, which were randomized to receive the same dose of the drug, but this time, instead of placebo, would receive $500 \mathrm{mg} /$ day of zidovudine (ZDV) in a doubleblind scheme. The group treated with antimalarial showed a significant decrease of viral RNA in plasma, after 16 weeks of treatment, maintaining a stable level of $\mathrm{CD}^{+}{ }^{+} \mathrm{T}$ cells, and low levels of interleukin-6 (IL-6) and immunoglobulin $\mathrm{G}(\mathrm{IgG})$ after treatment. The group treated with ZDV also had significantly lower viral load, but there were no changes of great magnitude in serum levels of IL-6 or IgG. Given that high levels of IL-6 are usually associated with a higher risk of progression of HIV, these results were encouraging with HCQS in terms of immune modulation, since these are usually favorable and can contribute to the overall effectiveness of therapy at least in some infected patients [1]; [36].

Paton and Aboulhab (2005) [37] in a recent study using a lower dose of HCQS (200 mg/day), hydroxyurea and didanosine - reverse transcriptase inhibitor - prove a significant reduction of viral load in about half of the patients, with levels undetectable at the end of the study, remaining constant the level of $\mathrm{CD}^{+} \mathrm{T}$ lymphocytes.At first, the idea to fabricate dosage forms containing a relatively inexpensive drug for the therapy of acquired immunodeficiency syndrome (AIDS) was considered plausible, aiming to use them in less wealthy countries with high rates of HIV infection. In contrast, the availability of generic drugs at low cost and government support in such treatment reduced the urgency and concern about the approach. However, the use of 
HCQ adjuvant in fixed dose combination with certain drugs for the treatment of AIDS has been widely discussed [38-39].The antimicrobial mechanism of this action seems to be the alkalinization of acidic intracellular vesicles, which inhibit the growth of microorganisms.

Studies also suggest that the reduction in the viral load in HIV infection occurs due to disturbance of post-translational glycosylation of envelope protein of the virus (gp120 protein), resulting in reduced infectivity of newly produced viral particles [39-41].The risks of the treatment with HCQS are relatively low. Overall, it correspond to gastrointestinal intolerance (nausea, vomiting, abdominal pain), skin hyperpigmentation, bleaching of hair, headache, dizziness. However, it remains a specific potential for more serious adverse events such as retinal damage (retinopathy) and neuromyotoxicity [1]; [42-44].

Many of these adverse effects seem to be due to increased endosomal $\mathrm{pH}$, which changes the processing of certain proteins and the binding to receptors of biological components. Other studies have postulated different mechanisms, such as strong links in vitro drug: nucleic acids and inhibition of calcium signaling in cells lymphoid cells [45-46].Ocular and cutaneous adverse effects of HCQ are possibly phototoxic reactions. Reports of drug substances that cause phototoxicity, a significant number of them contain chlorine, such as HCQ. It is suggested that the free radical chloride, formed from breaking the C-Cl bond, is the one responsible for the damage, since this combines with skin proteins [47-49].For reasons such as these, the use of antimalarials requires regular medical supervision and monitoring.Ocular toxicity associated with antimalarial agents was first observed in 1957. In 1959, Hobbs \& Sorsby recognized for the first time the retinal toxicity associated with the use of HCQ [50-51].Studies show that the frequency of retinopathy caused by accumulation of HCQ ranges from 0.001 to $40 \%$, but millions of people use the medicine for various purposes. However, ophthalmologic toxicity of this drug is a serious concern, because even after withdrawal of medication, there is little or no visual recovery, and sometimes there is progression of visual loss [52-56].

The mechanism causing ocular toxicity is not well understood. Antimalarial agents have acute effects on the metabolism of retinal cells, including photoreceptors. However, it is unclear whether these metabolic effects are the causes of the slow and chronic damage, in short-term, that characterize the clinical status of toxicity. HCQ binds to melanin in the retinal pigment epithelium, and this bond concentrate HCQ and contribute or prolong its toxic effects [57].New data showed that the risk of toxicity increases sharply to $1 \%$ after 5 to 7 years of use, or a cumulative dose of $1000 \mathrm{~g}$ HCQS, considering that the single dose is generally $400 \mathrm{mg}$ or calculated by weight dependence. The risk increases with continued use of the drug. Renal or hepatic failure should be considered, since these are the organs responsible for drug clearance. Age, genetic factors and patients with maculopathy should also be considered as causal factors for treatment discontinuation. Prolonged treatment is not recommended in children and in patients with hypersensitivity to 4-aminoquinolines [57].It is recommended to patients who will undergo the use of antimalarial drugs an initial examination to serve as a reference point and to discard maculopathy. This is a worsening of retinopathy of genetic nature, which may prove to be a contraindication to the use of these therapeutic agents. The protocol of annual screening should begin after 5 (five) years of continuous drug exposure. Tests such as multifocal electroretinography, optical coherence tomography, background autofluorescence, beyond the usual tests as visual field and fundus examinations are highly recommended [57].

It is advised that patients should be aware of the risk of toxicity and fundamentals for screening, aiming to detect, or minimize the impact of the effect. The drugs should be discontinued, if possible, when toxicity is recognized or strongly suspected. This is a decision to be taken together: patients and their physicians [57].The use of the drug in question is secure during pregnancy, because the molecule is large and HCQ is not able to cross the placental barrier. Cross-sectional studies suggest that it is possible to reduce the risk of fetal cardiac abnormalities in mothers with autoantibodies against antigens that participate in processes that involve RNA polymerase [58-61].

\section{PHARMACOKINETIC ASPECTS}

The HCQS is marketed and administered to patients as racemate, equimolar mixture of two enantiomers: (+)-HCQ and (-)-HCQ. However, no information is available about the possibility of stereoselective disposition and pharmacological activities of the isolated enantiomers [2]; [62].Despite this fact, 
many studies seek to measure the concentration of each of the enantiomers of HCQ and its respective metabolites. McLachlan and collaborators (1993) [3] suggested the existence of the action of one or more stereoselective processes in the arrangement of the molecule of HCQ in plasma and urine. Such processes are: chiral inversion, absorption, distribution and renal excretion. Nevertheless,

considering the stability of vicinal groups of chiral center in the molecule, the possibility of chiral inversion seems remote. The others showed to be stereoselective [2]; [63-66].The high concentrations of R-(-)HCQ in the blood and plasma compared to those seen with (+)-S-HCQ, confirm the existence of stereoselective processes in the disposition of the drug. It is postulated that the enantiomers $(\mathrm{R})$ is preferably concentrated by cellular blood compounds, and once set, would leave the (S) enantiomer longer available for metabolism. However, studies show that this and other stereoselective processes have significant variability between different individuals [2]; [66-67].There is no information available which ensure the efficacy and toxicology of each of the enantiomers. It is also unclear which of them is responsible for the antiarthritic activity. Haberkorn and collaborators (1979) [68] showed limited toxicity data in mice showing that R-(+)-CQisomer is more toxic to possess lethal dose lower than its enantiomer (S). The work also demonstrates that the S(+)-CQ, which has a very similar structure to HCQ, showed to have more potent antimalarial activity that R-(-)$\mathrm{CQ}$, in mice. However, the simple structural similarity does not allow extrapolation of the data mentioned above for the treatment of RA [64].

The HCQS presents oral and intestinal absorption variables with bioavailability of approximately $74 \%$ and distributed throughout the body with prolonged retention in the eye, liver, skin, lungs, other areas rich in melanin. In the epidermis, the drug concentration can become 100 to 200 -fold higher than plasma levels. In the erythrocyte, concentration is 2 to 5 times greater than plasma, since HCQ has substantial capacity for protein binding [44]; [65]; [69].The metabolism of the 4-aminoquinoline derivative is complex and extensive. After long-term administration, the plasma contains significant levels of HCQ and its three major metabolites, which still have the chiral center. Therefore, all exist as pairs of enantiomers, eight different substances [70].The accumulation of the drug and its metabolites should be expected in chronic dosing. The compound has long plasma half-life, estimated to exceed 40 days, and soon it may reach high concentrations (6000-80000 times higher than the plasma level). In addition, the plasma half-life increases proportionally with increasing dose. Current studies are able to measure this pharmacokinetic parameter by HPLC in whole blood [3]; [44]; [69]; [71].

The main route of excretion is renal, with $23-25 \%$ of the excreted compound in its unmodified form, along with the metabolites. Ducharme and collaborators (1995) [72] observed more rapid elimination of the (S)(+)-HCQ enantiomer compared with the (R)- (-)-HCQ, probably due to more rapid hepatic metabolism and excretion. This result was corroborated by Fieger and collaborators (1993) [73]. The work has also showed that the metabolites derived from (S) enantiomers represented $80-90 \%$ of the dose recovered and urinary metabolites were not detected in the blood.Unlike what it was stated by Tett \& collaborators (1989) [3], although HCQ overdoses is rarely reported, seven cases were highlighted in a literature review performed by Marquardt and collaborators (2001) [74]. However, there is no harmonization of treatment of this situation.

\section{TECHNOLOGICAL ASPECTS}

Preformulation studies can be defined as the full investigation of the physico-chemical properties of the active, alone or combined with other excipients that make up a pharmaceutical ingredient formulation. Perhaps, it is the limiting step of product development and requires special attention throughout the industry involved in this process. Therefore, it is necessary to apply the philosophy of quality by design, once it must plan, eliminate or diminish interference and expenditure of resources [75].Therefore, when choosing a drug molecule to develop new, safe and effective therapeutic alternatives,

it is important to gather information regarding the intrinsic characteristics of the molecule.Regarding HCQS, Semeniuk and coworkers (2008) [4] demonstrated by techniques of crystallography and X-ray diffraction, the crystal structure projection and intermolecular interactions of the monocrystal drug. According to the study, each of the nitrogen atoms of the free base is a proton donor in intermolecular hydrogen bonds with 
the oxygen atoms of the sulfate anion. Moreover, because it is a sulfate salt, the formation of "supermolecules" containing two cations and two anions can be observed, it is the free base of the drug and sulfate, respectively. The study also compared the presence of the hydroxyl group in relation to its absence in chloroquine

phosphate, where it has been suggested that the addition of another proton donor appears to promote significant changes in the conformation of the molecule, however it increases the interaction with the transmembrane receptor of the parasite (putative receptor) [76].On the salt formation, it is suggested that synthesis of the sulfate salt is due to two parameters: solubility and melting point. The solubility of HCQS is $2,61.10^{-2} \mathrm{~g} / \mathrm{L}$, therefore classified as practically insoluble, according to the Brazilian Pharmacopoeia $5^{\text {th }}$ Edition [77-79]. Very little is known about the stability and other information of HCQS in the field of pharmaceutical technology. Officially, the British and American official compendia don't mention stability issues of HCQ such as impurities and degradation products [80-81]. However, some authors have demonstrated the existence of substances correlated from forced degradation studies.Tønnesen and collaborators (1988) [49] irradiated drug solutions in water and isopropanol using preparative HPLC to isolate impurities. Samples followed, then the analysis of NMR and mass spectrometer (MS) (isobutane chemical ionization). After only 5 hours of exposure, the irradiated sample in isopropanol originated a chromatogram with four different impurities (IMP): IMP -2 (desethyl-HCQ), IMP-3 (N-desidroxiethyl-HCQ), IMP-4 (dimer of HCQ) and IMP-5 (deaminated-HCQ).

Later, Dongre and colleagues (2009) [82] carried out the identification and characterization of two impurities related to the synthesis of the drug: the already mentioned IMP-2 and the novel one, the IMP-1 (Nquaternary HCQ). The identification and characterization of these substances was possible only by the use of hyphenated techniques, such as LCMS-IT analysis followed by ESI-TOF and NMR $\left({ }^{1} \mathrm{H},{ }^{13} \mathrm{C}\right.$, DEPT and 2D) of the drug and isolated impurities.More recently, Saini and Gulshan (2013) [83] in short communication conducted the first study of forced degradation. The work proved to be successful in its objective: to conduct the study of forced degradation, identifying all possible degradation products coming from the different reactions of hydrolysis, oxidation, photolysis, and dry heat.Virtually all proposed conditions showed stability of the drug, except the alkaline solution maintained under photolysis conditions. This solution showed six degradation products (Fig. 1): four unpublished (I-IV) and two products with similar structure to known impurities. The authors highlighted that the degradation products III-VI have intact the chromophore group of the drug, since they retain the same pattern of the UV absorption spectrum. While, the degradation products I and II show changes in the chromophore group Benzenoid. Thus, it was possible to characterize most of the degradation products, except VI, which offered little in the mass spectrum results; III is already known impurity, while I, II, IV and V were new degradation products elucidated by the authors.<smiles>CCN(CCO)CCCC(C)Nc1ccnc2cc(Cl)ccc12</smiles><smiles>CCCC(C)Nc1cc[n+](S)c2cc(Cl)ccc12</smiles><smiles>CCNCCCC(C)Nc1ccnc2cc(O)ccc12</smiles><smiles>CC(CCCN(CCO)C(=O)O)Nc1ccnc2cc(Cl)ccc12</smiles>

Figure 1. Structures of HCQ, its impurities and degradation products (adapted from Saini and Bansal, 2013[83]). 
To obtain these results, the authors were offered the following characterization techniques: LC-PDA, + ESI-MSn and LCMS-TOF; to elucidate the most probable route of degradation level (Fig. 2), as well as the intrinsic characteristics of the drug stability.

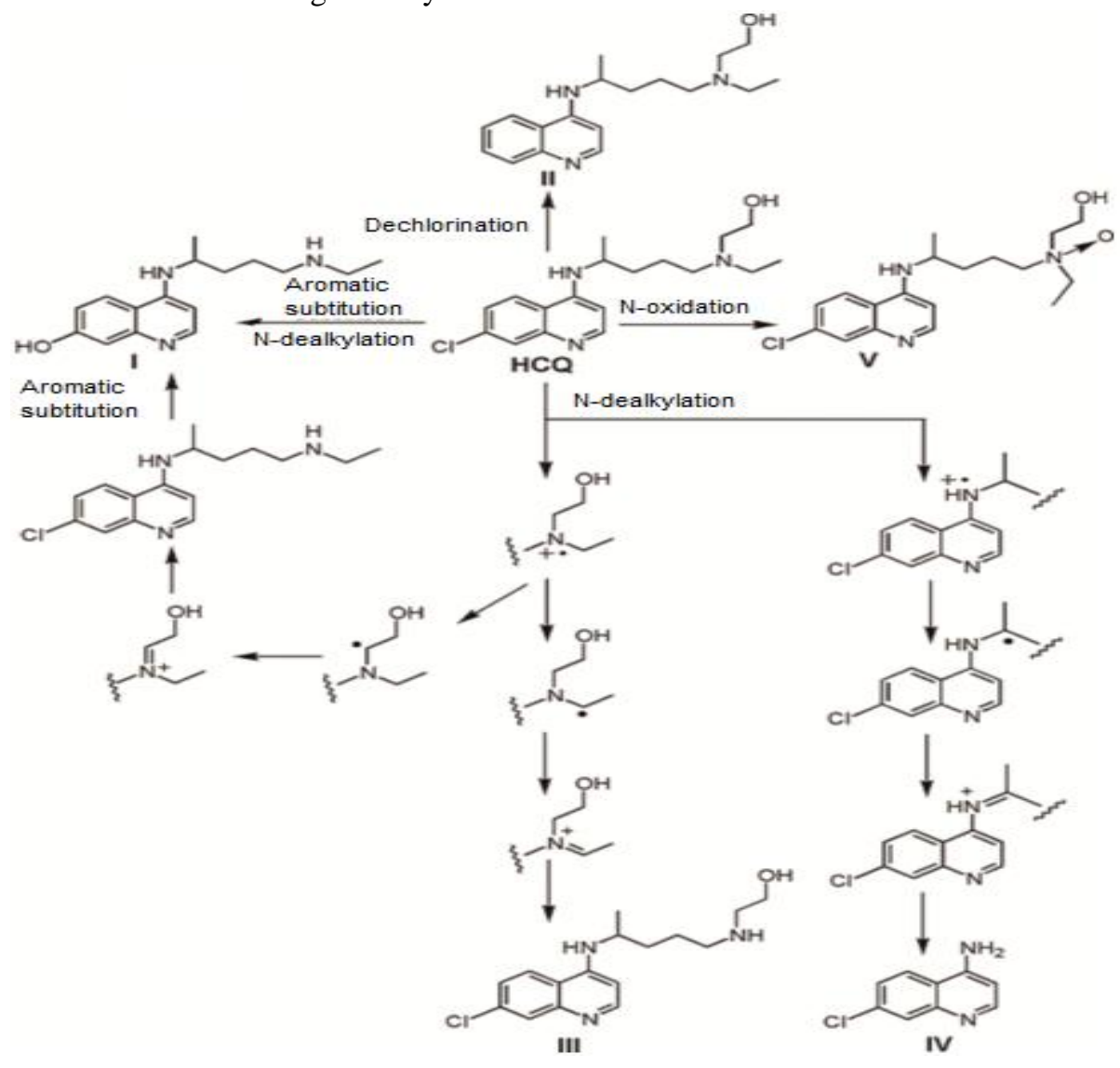

Figure 2. Probable degradative route of HCQS.

The use of HCQS requires attention, because it is commercialized in the racemic form. The use of racemic mixtures can contribute to toxicity or adverse drug effects, particularly when they are associated with pharmacologically inactive or less active isomers. Practical example: thalidomide. Just one of its enantiomers is able to promote sedation. When metabolized, the molecule undergoes racemization in vivo and just the most toxic form is absorbed, responsible for the notorious birth defects [84-87]. Then, it is necessary to better clarify the physico-chemical properties and stereoselective profiles - kinetic and dynamic - of chiral drugs. Hence, drugs that are already marketed as racemates have been studied to assess whether there is an advantage in producing its pure enantiomer [84]; [86].

Therefore, the development of analytical methods capable of separating isomers in known concentrations, in biological or pharmaceutical preparations, has become an essential requirement in quality control and pharmacokinetic [86]; [88].Most studies of enantiomeric separation, techniques have been developed using capillary electrophoresis and, more commonly, high performance liquid chromatography (HPLC). For the success of HPLC, three procedures may be used: chiral derivatization, addition of chiral additive to the mobile phase and use of chiral stationary phase (chiral column) [49]; [82]; [89-91]. The chiral derivatization involves a reaction of the mixture of enantiomers with a chiral derivatizing agent, enantiomerically pure, to form two diastereomeric derivatives. Then, the diastereomers may be separated using HPLC on eluting mode in the reversed phase or normal phase. In the case of HCQS, there are three sites of formation of diastereomers: aromatic nitrogen, tertiary aliphatic nitrogen and hydroxyl group; as shown in Fig. 3 [82]; [86]. 


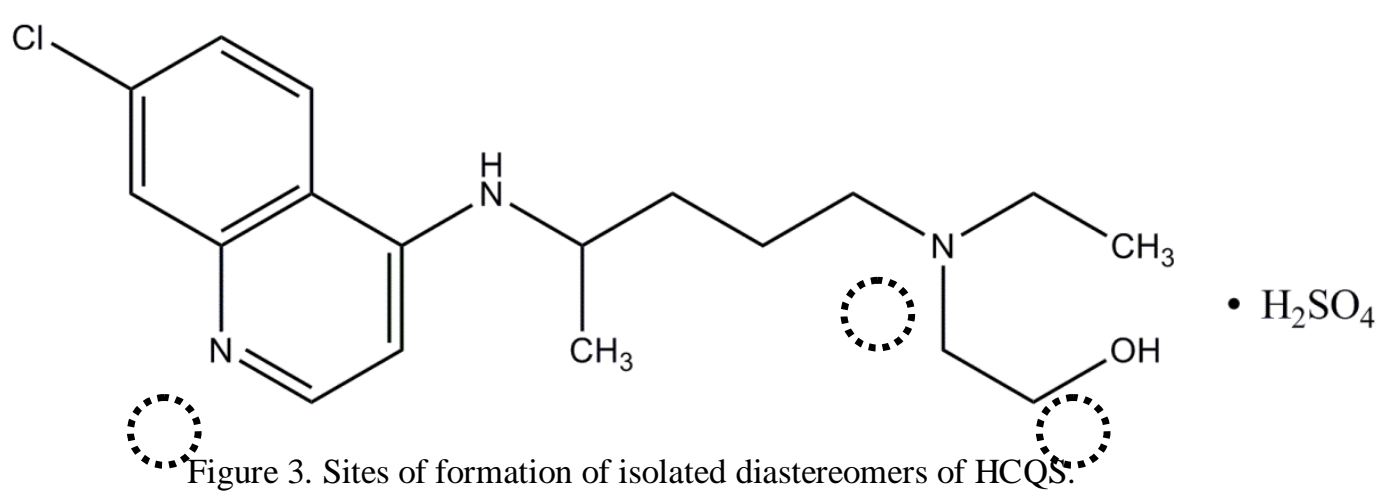

The use of (+)-di-O-acetyl-L-tartaric acid anhydride (DATAAN) as the derivatization reagent was first reported by Lindner and collaborators (1991) [92]. The work includes the use of DATAAN for the separation of the enantiomers of various $\beta$-adrenoceptor antagonists, including propranolol. Instead of the amino function, DATAAN preferentially reacts with the hydroxyl group of $\beta$-blockers to form esters, which justifies its use for HCQS. Further studies demonstrate the use of other derivatizing agents, such as S-(+)-1-(1-naphthyl)ethyl isocyanate and S-(+)-1-(1-phenyl)ethyl isocyanate [64].

In addition chiral additive - High enantiomeric separation mechanism -, one chiral selector is added to the mobile phase. Transient diastereomeric complexes formed between the analyte and the mobile phase plus the chiral selector may also be separated by the HPLC on elution mode in the reversed phase or normal phase [86]; [93].The method using chiral column - third and final method presented here - seems to be the most applied. The procedure involves using a chiral selector chemically bound to the stationary phase. Recent methods use the $\alpha 1$-acid glycoprotein as the bound agent. Such a system is able to interact with the two enantiomers of the analyte, forming transient diastereomeric complexes through hydrogen bonds, $\pi-\pi$ interactions, inclusion complexes and steric avoidance, leading consecutively to enantioseparation [86]; [94-97].

The large standoff encountered in the development of analytical methods for enantioseparation lies in obtaining the isolated compounds with high purity. Chemical reference substances of drugs, metabolites and their isomers are expensive or nonexistent. Therefore, some studies use internal standards. Ofori-Adjei and collaborators (1986) [98] incubated (R) and (S) isomers of chloroquine separately with human liver microsomes, in vitro, producing optically pure enantiomers of metabolites, subsequently used as standard.In the case of HCQ, the racemic mixture contains two isomers: (-)-(R)-HCQ and (+)-(S)-HCQ. The biological metabolism of the drug promotes the formation of three main active metabolites: Desethylchloroquine (DCQ) desethylhydroxychloroquine (DHCQ) and bisdesethylchloroquine (BDCQ), all chiral compounds [70]; [72]; [99].

The methods described for the enantioselective analysis of HCQ and its main metabolites using HPLC techniques include two-step analysis. The analytes include: pharmaceutical preparations, urine, plasma and whole blood.Another way to assess the stability of a drug is thermodegradation. Often it can be measured by thermogravimetric analysis, a technique capable of assessing the interdependence of the mass variation which occurs in the sample - gain or loss - as a function of time (at a given constant temperature) or temperature [100]. However, there is no currently information in the literature about thermal behavior and stability of the solid form of HCQ sulfate.

\section{CONCLUSION}

Despite the classical indication as an antimalarial drug, HCQS is presenting a diversity of clinical evidence that awaken the search for a better understanding of their biological properties. Among the activities reported in the literature, there are indications for the treatment of autoimmune diseases such as lupus and RA, where the drug is already an established alternative therapy. Reports also reveal the effectiveness of HCQS in different diseases from those present in rheumatic conditions, such as improved insulin sensitivity, ability to reduce thromboembolic events, reduction of lipid levels and treatment of infection by HIV. 
The found evidences reinforce the need for special care in the treatment management in long term with HCQS, since the ocular and cutaneous adverse effects, possible phototoxic reactions, can cause irreversible damage. The biological metabolism of HCQS promotes the formation of three active and chiral metabolites, a fact that encourages the development of studies that evaluate the kinetic behavior of these metabolites and the intrinsic characteristics of the drug, because the literature has been reported in a preliminary form.

\section{REFERENCES}

[1] N.J. Olsen, M.A. Schleich and D.R. Karp, Multifaceted effects of hydroxychloroquine in human disease, Semin Arthritis Rheum., 43(2), 2013, 264-72.

[2] A.J. McLachlan, S.E. Tett, D.J. Cutler and R.O. Day, Disposition of the enantiomers of hydroxychloroquine in patients with rheumatoid arthritis following multiple doses of the racemate, Br J Clin Pharmacol., 36(1), 1993, 78-81.

[3] S.E. Tett, D.J. Cutler, R.O. Day and K.F. Brown. Bioavailability of hydroxychloroquine tablets in healthy volunteers, Br $J$ Clin Pharmacol., 27(6), 1989, 771-79.

[4] A. Semeniuk, A. Niedospial, J. Kalinowska-Tluscik, W. Nitek and B. J. Oleksyn, Molecular geometry of antimalarial amodiaquine in different crystalline environments, J Mol Struct., 875(1-3), 2008, 32-41.

[5] T.A. Shapiro and D.D. Goldberg, Quimioterapia das infecções por protozoários, In: L.S. Goodman; A. Gilman, As Bases Farmacológicas da Terapêutica, (Rio de Janeiro: McGraw-Hill; 2006) 927-9.

[6] C. Gaujoux-Viala, J.S. Smolen, R. Landewé, M. Dougados, T.K. Kvien, E.M. Mola, M. Scholte-Voshaar, P. Van Riel and L. Gossec, Current evidence for the management of rheumatoid arthritis with synthetic disease-modifying antirheumatic drugs: a systematic literature review informing the EULAR recommendations for the management of rheumatoid arthritis, Ann Rheum Dis., 69(6), 2010, 1004-9.

[7] K. Pavelka, K.P. Sen, Z. Pelísková, J. Vácha and K. Trnavský, Hydroxychloroquine sulphate in the treatment of rheumatoid arthritis: a double blind comparison of two dose regimens, Ann Rheum Dis, 48(7), 1989, 542-546.

[8] I.H. Nuver-Zwart, P.L. van Riel, L.B. van de Putte and F.W. Gribnau. A double-blind comparative study of sulphasalazin and hydroxychloroquine in rheumatoid arthritis: evidence of an earlier effect of sulphasalazin. Ann Rheum Dis, 48, 1989, 389-395.

[9] The Canadian Hydroxychloroquine Study Group, A Randomized Study of the Effect of Withdrawing Hydroxychloroquine Sulfate in Systemic Lupus Erythematosus, N Engl J Med, 324, 1991, 150-154.

[10] N. Costedoat-Chalumeau, G. Leroux, J.C. Piette and Z. Amoura, Why all systemic lupus erythematosus patients should be given hydroxychloroquine treatment?, Joint Bone Spine, 77(1), 2010, 4-5.

[11] B.J. Fessler, G.S. Alarcón, G. Jr. McGwin, J. Roseman, H.M. Bastian, A.W. Friedman, B.A .Baethge, L. Vilá and J.D. Reveille. Systemic lupus erythematosus in three ethnic groups: XVI. Association of hydroxychloroquine use with reduced risk of damage accrual, Arthritis Rheum., 52(5), 2005, 1473-80.

[12] G. Ruiz-Irastorza, M. Ramos-Casals, P. Brito-Zeron and M.A. Khamashta, Clinical efficacy and side effects of antimalarials in systemic lupus erythematosus: a systematic review, Ann Rheum Dis, 69(1), 2010, 20-8.

[13] S.K. Shinjo et al., Antimalarial treatment may have a time-dependent effect on lupus survival: data from a multinational Latin American inception cohort, Arthritis Rheum, 62, 2010, 855-862.

[14] J.A. James et al., Hydroxychloroquine sulfate treatment is associated with later onset of systemic lupus erythematosus, Lupus, 16, 2007, 401-409.

[15] C. Francès, A. Cosnes, P. Duhaut, N. Zahr, B. Soutou, S. Ingen-Housz-Oro, D. Bessis, J. Chevrant-Breton, N. Cordel, D. Lipsker and N. Costedoat-Chalumeau, Low blood concentration of hydroxychloroquine in patients with refractory cutaneous lupus erythematosus: a French multicenter prospective study, Arch Dermatol, 148(4), 2012, 479-84.

[16] G.J. Pons-Estel, G.S. Alarco, G. McGwin, M.I. Danila and J. Zhang, H.M. Bastian, et al., Protective effect of hydroxychloroquine on renal damage in patients with lupus nephritis: LXV, data from a multiethnic US cohort, Arthritis Rheum., 61(6), 2009, 830-9.

[17] N. Kasitanon, L.S. Magder and M. Petri, Predictors of survival in systemic lupus erythematosus, Medicine (Baltimore), 85(3), 2006, 147-56.

[18] A. Quatraro, G. Consoli, M. Magno, F. Caretta, A. Nardozza, A. Ceriello and D. Giugliano, Hydroxychloroquine in decompensated, treatment-refractory noninsulin-dependent diabetes mellitus. A new job for an old drug?. Ann Intern Med., 112(9), $1990,678-81$.

[19] E. Mercer, L. Rekedal, R. Garg, B. Lu, EM. Massarotti and D.H. Solomon, Hydroxychloroquine improves insulin sensitivity in obese non-diabetic individuals, Arthritis Res Ther., 14(3), 2012, 135.

[20] R. Johnson and J. Charnley, Hydroxychloroquine in prophylaxis of pulmonary embolism following hip arthroplasty, Clin Orthop Relat Res., 144, 1979, 174-7.

[21] R. Kaiser, C.M. Cleveland and L.A. Criswell, Risk and protective factors for thrombosis in systemic lupus erythematosus: results from a large, multiethnic cohort, Ann Rheum Dis., 68(2), 2009, 238-41.

[22] D.J. Wallace, Does hydroxychloroquine sulfate prevent clot formation in systemic lupus erythematosus? Arthritis Rheum., 30(12), 1987, 1435-6.

[23] E. Ernst, M. Rose and R. Lee, Modification of transoperative changes in blood fluidity by hydroxychloroquine: a possible explanation for the drug's antithrombotic effect, Pharmatherapeutica, 4(1), 1984, 48-52.

[24] E. Johansson, K. Forsberg and H. Johnsson, Clinical and experimental evaluation of the thromboprophylactic effect of hydroxychloroquine sulfate after total hip replacement, Haemostasis, 10(2), 1981, 89-96.

[25] C. Prowse, D. Pepper and J. Dawes, Prevention of the platelet alpha-granule release reaction by membrane-active drugs, Thromb Res., 25(3), 1982, 219-27. 
[26] M. Petri, C. Lakatta, L. Magder and D. Goldman, Effect of prednisone and hydroxychloroquine on coronary artery disease risk factors in systemic lupus erythematosus: a longitudinal data analysis, Am J Med., 96(3), 1994, 254-9.

[27] P. Rahman, D.D. Gladman, M.B. Urowitz, K. Yuen, D. Hallett and I.N. Bruce, The cholesterol lowering effect of antimalarial drugs is enhanced in patients with lupus taking corticosteroid drugs, J Rheumatol, 26(2), 1999, 325-30.

[28] E. Cairoli, M. Rebella, N. Danese, V. Garra and E. Borba, Hydroxychloroquine reduces low-density lipoprotein cholesterol levels in systemic lupus erythematosus: a longitudinal evaluation of the lipid-lowering effect, Lupus, 21(11), 2012, $1178-82$.

[29] S.J. Morris, M.C. Wasko, J.L. Antohe, J.A. Sartorius, H.L. Kirchner, S. Dancea, et al., Hydroxychloroquine use associated with improvement in lipid profiles in rheumatoid arthritis patients, Arthritis Care Res (Hoboken), 63(4), 2011, 530-4.

[30] H. Mirjafari, A. Al-Husain and I.N. Bruce, Cardiovascular risk factors in inflammatory arthritis, Curr Opin Lipidol, 22(4), 2011, 296301.

[31] J.R. O’Dell, K.W. Blakely, J.A. Mallek, P.J. Eckhoff, R.D. Leff, S.J. Wees, et al., Treatment of early seropositive rheumatoid arthritis: a two-year, double-blind comparison of minocycline and hydroxychloroquine, Arthritis Rheum., 44(10), $2001,2235-41$.

[32] A. Kavanaugh, B. Adams-Huet, R. Jain, M. Denke and J. McFarlin, Hydroxychloroquine effects on lipoprotein profiles (the HELP trial): a double-blind, randomized, placebo-controlled, pilot study in patients with systemic lupus erythematosus, J Clin Rheumatol., 3(1), 19973-8.

[33] R. Munro, E. Morrison, A.G. McDonald, J.A. Hunter, R. Madhok and HA. Capell, Effect of disease modifying agents on the lipid profiles of patients with rheumatoid arthritis, Ann Rheum Dis, 56(6), 1997, 374-7.

[34] J.C. Sachet, E.F. Borba, E. Bonfa, C.G. Vinagre, V.M. Silva and R.C. Maranhão, Chloroquine increases low-density lipoprotein removal from plasma in systemic lupus patients, Lupus, 16(4), 2007, 273-8.

[35] K. Sperber, M. Louie, T. Kraus, J. Proner, E. Sapira, S. Lin, et al., Hydroxychloroquine treatment of patients with human immunodeficiency virus type 1, Clin Ther., 17(4), 1995, 622-36.

[36] K. Sperber, G. Chiang, H. Chen, W. Ross, E. Chusid, M. Gonchar, et al., Comparison of hydroxychloroquine with zidovudine in asymptomatic patients infected with human immunodeficiency virus type 1, Clin Ther., 19(5), 1997, 913-23.

[37] N.I. Paton and J. Aboulhab, Hydroxychloroquine, hydroxyurea and didanosine as initial therapy for HIV-infected patients with low viral load: safety, efficacy and resistance profile after 144 weeks. HIV Med, 6(1), 2005, 13-20.

[38] L. Aguirre-Cruz, K.J. Torres, H. Jung-Cook, C. Fortuny, E. Sanchez, A. Soda-Mehry, et al., Short communication: preferential concentration of hydroxychloroquine in adenoid tissue of HIV-infected subjects, AIDS Res Hum Retroviruses, 26(3), 2010, 339-42.

[39] A. Savarino, L. Gennero, K. Sperber and J.R. Boelaert, The anti-HIV-1 activity of chloroquine, J Clin Virol., 20(3), 2001, 131-5.

[40] J.M. Rolain, P. Colson and D. Raoult, Recycling of chloroquine and its hydroxyl analogue to face bacterial, fungal and viral infections in the 21st century, Int J Antimicrob Agents, 30(4), 2007, 297-308.

[41] G. Chiang, M. Sassaroli, M. Louie, H. Chen, V.J. Stecher and K. Sperber, Inhibition of HIV-1 replication by hydroxychloroquine: mechanism of action and comparison with zidovudine, Clin Ther, 18(6), 1996, 1080-92.

[42] M.F. Marmor, U. Kellner, T.Y. Lai, J.S. Lyons and W.F. Mieler, American Academy of Ophthalmology. Revised recommendations on screening for chloroquine and hydroxychloroquine retinopathy, Ophthalmology, 118(2), 2011, 415-22.

[43] F. Wolfe and M.F. Marmor, Rates and predictors of hydroxychloroquine retinal toxicity in patients with rheumatoid arthritis and systemic lupus erythematosus, Arthritis Care Res, 62(6), 2010, 775-84.

[44] L. Tanenbaum and D.L. Tuffanelli, Antimalarial agents, Arch. Dermatol, 116, 1980; 587-591.

[45] A. Kuznik, M. Bencina, U. Svajger, M. Jeras, B. Rozman and R. Jerala, Mechanism of endosomal TLR inhibition by antimalarial drugs and imidazoquinolines, J Immunol, 186(8), 2011, 4794-804.

[46] F.D. Goldman, A.L. Gilman, C. Hollenback, R.M. Kato, B.A. Premack and D.J. Rawlings, Hydroxychloroquine inhibits calcium signals in T cells: a new mechanism to explain its immunomodulatory properties, Blood, 95(11), 2000, 3460-6.

[47] D.E. Moore and V.J. Hemmens, Photosensitization by anti-malarial drugs, Photochem Photobiol., 36, 1982, $71-77$.

[48] D.E. Moore and S.R. Tamat, Photosensitizing by drugs: photolysis of some chlorine-containing drugs, J. Pharm. Pharmacol., 32, 1980, 172-77.

[49] H.H. Tønnesen, A.L. Grislingaas, S.O. Woo and J. Karlsen, Photochemical stability of antimalarials, Int J Phar, 43, $1988,215-219$.

[50] H.E. Hobbs, A. Sorsby and A. Dreedman. Retinopathy following chloroquine therapy, Lancet, 2, 1959, 478-80.

[51] D.V. Weinberg and D.J. D’Amico, Retinal toxicity of systemic drugs. In: Albert DM, Jakobiec FA (Ed.), Principles and practice of ophthalmology: clinical practice, (Philadelphia: W.B. Saunders, 1994) 3284-5.

[52] M. Easterbrook, The ocular safety of hydroxychloroquine, Semin Arthritis Rheum, 23(2 Suppl 1), $1993,62-67$.

[53] M.F. Raines, S.K. Bhargava and E.S. Rosen, The blood-retinal barrier in chloroquine retinopathy, Invest Ophthalmol Vis Sci, 30, 1989, 1726-31.

[54] A. Elman, R. Gullberg, E. Nilsson, et al, Chloroquine retinopathy in patients with rheumatoid arthritis, Scand J Rheumatol, 5, 1976, $161-6$.

[55] H.E. Hobbs, S.P. Eadie and F. Somerville. Ocular lesions after treatment with chloroquine, Br J Ophthalmol, 45(4), 1961, $284-97$.

[56] P. Henkind and N.F. Rothfield, Ocular abnormalities in patients treated with synthetic antimalarial drugs, $N$ Engl $J$ Med, 269, 1963, 433-9.

[57] M.F. Marmor, U. Kellner, T.Y. Lai, J.S. Lyons and W.F. Mieler, MD, American Academy of Ophthalmology Revised Recommendations on Screening for Chloroquine and Hydroxychloroquine Retinopathy, Ophthalmol., 118(2), $2011,415-422$.

[58] N. Costedoat-Chalumeau, Z. Amoura, D.L. Huong, P. Lechat and JC, Piette Safety of hydroxychloroquine in pregnant patients with connective tissue diseases. Review of the literature, Autoimmun Rev., 4(2), 2005, 111-5.

[59] P.M. Izmirly, M.Y. Kim, C. Llanos, P.U. Le, M.M. Guerra, A.D. Askanase, J.E. Salmon and J.P. Buyon, Evaluation of the risk of anti-SSA/Ro-SSB/La antibody-associated cardiac manifestations of neonatal lupus in fetuses of mothers with systemic lupuserythematosus exposed to hydroxychloroquine, Ann Rheum Dis., 69(10), 2010, 1827-30. 
[60] P.M. Izmirly, N. Costedoat-Chalumeau, C.N. Pisoni, M.A. Khamashta, M.Y. Kim, A. Saxena, D. Friedman, C. Llanos, J.C. Piette and J.P. Buyon. Maternal use of hydroxychloroquine is associated with a reduced risk of recurrent anti-SSA/Ro-antibody-associated cardiac manifestations of neonatal lupus, Circulation, 126(1), 2012; 76-82.

[61] R.A. Levy, O uso de drogas anti-reumáticas na gravidez, Rev Bras Reumatol, 45(3), 2005, 124-33.

[62] T.W.G. Solomons and C.B. Fryhle. Química Orgânica (Rio de Janeiro: LTC, 2005).

[63] D.R. Brocks and R. Mehvar, Stereoselectivity in the Pharmacodynamics and Pharmacokinetics of the Chiral Antimalarial Drugs, Clin Pharmacokinet, 42(15), 2003, 1359-82.

[64] D.R. Brocks, F.M. Passutto and F. Jamali, Analytical and semi-preparative high-performance liquid chromatographic separation and assay of hydroxychloroquine enantiomers, J Chromatogr, 581, 1992, 83-92.

[65] J. Ducharme, I.W. Wainer, H.I. Parenteau and J.H. Rodman, Stereoselective distribution of hydroxychloroquine in the rabbit following single and multiple oral doses of the racemate and the separate enantiomers, Chirality, 6(4), 1994, 337-46.

[66] A.J. McLachlan, S.E. Tett, D.J. Cutler and R.O. Day, Disposition and absorption of hydroxychloroquine enantiomers following a single dose of the racemate, Chirality, 6(4), 1994, 360-64.

[67] L.L. Gustafsson, B. Nordmark, O. Ericsson and J. Hermansson, The pharmacokinetics of (+)-and (-)-chloroquine in patients with rheumatoid arthritis [abstract], $3^{\text {rd }}$ World Conference of Clinical Pharmacology and Therapeutics. Stockholm, Sweden, 1986.

[68] A. Haberkorn, H.P. Kraft and G. Blaschke, Antimalarial activity of the optical isomers of chloroquine diphosphate, Tropenmed Parasitol, 30(3), 1979, 308-12.

[69] J.J. Kanski, Oftalmologia Clínica uma Abordagem Sistemática (Rio de Janeiro: Revinter, 2000).

[70] J. Iredale, H. Fieger and I.W. Wainer, Determination of the stereoisomers of hydroxychloroquine and its metabolites in plasma and urine following a single oral administration of racemic hydroychloroquine, Semin. Arthritis Rheum., 23(2-1), 1993, 74-81.

[71] N. Costedoat-Chalumeau, Z. Amoura, J.S. Hulot, H.A. Hammoud, G. Aymard, P. Cacoub, et al, Low blood concentration of hydroxychloroquine is a marker for and predictor of disease exacerbations in patients with systemic lupus erythematosus, Arthritis Rheum, 54:32, 2006, 84-90.

[72] J. Ducharme, H. Fieger, M.P. Ducharme, S.K. Khalil and I.W. Wainer, Enantioselective disposition of hydroxychloroquine after oral of the racemate to healthy subjects, Br J Clin Pharmacol, 40(2), 1995, 27-133.

[73] H. Fieger, J. Iredale and I.W. Wainer, Enantioselective determination of hydroxychloroquine and its major metabolites in urine and the observation of a reversal in the (+)/(-)-hydroxychloroquine ratio, Chirality, 5(2), 1993, 65-70.

[74] K. Marquardt and T.E. Albertson, Treatment of hydroxychloroquine overdose, Am J Emerg Med. 19(5), 2001, 420-24.

[75] L.D. Moretto and J. Calixto, Boas práticas de desenvolvimento de produtos (São Paulo: SINDUSFARMA: Sindicato da Indústria de Produtos Farmacêuticos no Estado de São Paulo, 2009).

[76] F.C. Koyama, Caracterização de putativo receptor serpentino e estudos sobre a implicação do sistema de ubiquitina/proteossomo na modulação do ciclo celular de Plasmodium falciparum., doctoral diss., Universidade de São Paulo, São Paulo, 2012.

[77] Brasil, Farmacopéia Brasileira (Brasília: Agência Nacional de Vigilância Sanitária, 2010).

[78] S. Sweetana and M.J. Akers, Solubility principles and practices for parenteral drug dosage form development, PDA J Pharm Sci Technol, 50(5), 1996, 330-42.

[79] University of Alberta. In: drugbank version 3.0. 2013. Avaiable at: < http://www.drugbank.ca/>. Access in: 29 out 2014.

[80] British pharmacopoeia (London: HM stationary office, 2008).

[81] The United States Pharmacopoeia - National Formulary (Rockville: The United States Pharmacopeial Convention, 2010).

[82] V.G. Dongre, P.D. Ghugare, P. Karmuse, D. Singh, A. Jadhav and A. Kumar. Identification and characterization of process related impurities in chloroquine and hydroxychloroquine by LC/IT/MS, LC/TOF/MS and NMR, J Pharm Biomed Anal., 49(4), 2009, 873-9.

[83] B. Saini and G. Bansal, Characterization of four new photodegradation products of hydroxychloroquine through LC-PDA, ESI-MSn and LC-MS-TOF studies, J Pharm Biomed Anal, 84, 2013, 224-31.

[84] J. Caldwell. Stereochemical determinants of the nature and consequences of drug metabolism, J chromatogr, 694, 1995, 39-48.

[85] J. Caldwell, Importance of stereospecific bioanalytical monitoring in drug development, J Chromatogr, 719, 1996, 3-13.

[86] C.D. Cardoso, Avaliação da Cromatografia Líquida de Alta Eficiência e Eletroforese Capilar no Estudo in vitro do Metabolismo Enantiosseletivo da hidroxicloroquina, doctoral diss., Universidade de São Paulo, Ribeirão Preto, 2006.

[87] L.M. Lima, C.A.M. Fraga and E.J. Barreiro, O renascimento de um fármaco: talidomida, Quím Nova, 24(5), 2001, 683-88.

[88] K. Verleysen and P. Sandra, Separation of chiral compounds by capillary electrophoresis, Electrophoresis, 19(16-17), 1998, 2798-33.

[89] K. Fried and I.W. Wainer, Column-switching techniques in the biomedical analysis of stereoisomeric drugs: why, how and when, $J$ Chromatogr B., 689, 1997, 91-104.

[90] K. Tachibana and A. Ohnishi, Reversed-phase liquid chromatographic separation of talidomida, Quím Nova, 24(5), 2001, 683-88.

[91] L.Z. Wang, R.Y. Ong, T.M. Chin, W.L. Thuya, S.C. Wan, A.L. Wong, S.Y. Chan, P.C. Ho and B.C. Goh, Method development and validation for rapid quantification of hydroxychloroquine in human blood using liquid chromatography-tandem mass spectrometry, $J$ Pharm Biomed Anal, 61, 2012, 86-92.

[92] W. Lindner, M. Rath, K. Stoschitzky and G. Uray, Improved Enantiospecific RP-HPLC Assays for Propranolol in Plasma and Urine with Pronethalol as Internal Standard, J Anal Toxicol, 15(6), 1991, 327-331.

[93] P.S. Bonato, V.A.P. Jabor and C.M. Gaitani, Análise enantiosseletiva de fármacos: contribuições da cromatografia líquida de alta eficiência e eletroforese capilar, Quím Nova, 28(4), 2005, 683-91.

[94] J. Iredale and I.W. Wainer, Determination of hydroxychloroquine and its major metabolites in plasma using sequential achiral—chiral high-performance liquid chromatography, J Chromatogr, 573(2), 1992, 253-8.

[95] A.J. McLachlan, S.E. Tett and D.J. Cutler, High-performance liquid chromatographic separation of the enantiomers of hydroxychloroquine and its major metabolites in biological fluids using an alpha 1 -acid glycoprotein stationary phase, J Chromatogr, 570(1), 1991, 119-127 
[96] A.K. Singh, E.R.M. Kedor-Hackmann and M.I.R.M. Santoro, Cromatografia líquida com fase quiral aplicada na separação enantiomérica de fármacos cardiovasculares, Rev Bras Cienc Farm, 42(4), 2006, 553-66.

[97] L.R. Snyder, J.J. Kirkland and J.L. Glajch, Chiral Separation, In: L.R. Snyder, J. J. Kirkland and J.L. Glajch (Ed.), Practical HPLC method development, 2 (New York: Wiley-Interscience, 1997) 537.

[98] D. Ofori-Adjei, O. Ericsson, B. Lindström, J. Hermansson, K. Adjepon-Yamoah and F. Sjöqvist, Enantioselective analysis of chloroquine and desethylchloroquine after oral administration of racemic chloroquine, Ther Drug Monit, 8(4), 1986, 457-61.

[99] E.W. McChesney, Animal toxicity and pharmacokinetics of hydroxychloroquine sulfate, Am J Med., 75(1A), 1983, 11-8.

[100] M.M. Conceição, Estudo da degradação térmica de adoçante com aspartame, doctoral diss., Universidade Federal da Paraíba, João Pessoa, 2004. 